\title{
Assessing Employees' Reactions to Organizational Change
}

\author{
Aimin Wang, Senay Kebede \\ School of Management, Wuhan University of Technology, Wuhan, China \\ Email: wangam@vip.163.com, Kebedesenay2@gmail.com
}

How to cite this paper: Wang, A. M., \& Kebede, S. (2020). Assessing Employees' Reactions to Organizational Change. Journal of Human Resource and Sustainability Studies, 8, 274-293.

https://doi.org/10.4236/jhrss.2020.83016

Received: July 11, 2020

Accepted: August 16, 2020

Published: August 19, 2020

Copyright $\odot 2020$ by author(s) and Scientific Research Publishing Inc. This work is licensed under the Creative Commons Attribution International License (CC BY 4.0).

http://creativecommons.org/licenses/by/4.0/ (c) (i) Open Access

\begin{abstract}
Employees have different reactions to change initiative, because they have different personal experiences, motivation levels, socio-demographic characteristics, knowledge, values and different behavior models. The aim of this study is examining employees' reaction to organizational change using the following specific perceptions: perceived organizational support, perceived procedural justice, perceived fear of consequences of a change, perceived self-confidence for learning and development, perceived trust in management and perceived need for change. The study used quantitative data by using survey method and structured survey questionnaires were distributed to 359 (three hundred fifty-nine employees in Mekelle Revenue and Custom Authority (MRCA) in seven branches were selected by using stratified sampling technique). Beside this simple random sampling technique used to select the employees as respondent. SPSS used for data analysis. The result of this study suggests that measuring employees' reaction is important for effective organizational change and further studies are important to solve the problems.
\end{abstract}

\section{Keywords}

Organizational Change, Perception, Resistance to Change, Support to Change, Reaction to Change

\section{Introduction}

Employee's reaction to organizational change is one of the important issues in change management studies. Employees may have a positive or negative perception/attitude towards change. Employee attitudes and behaviors to accept organizational change considered important for management and change agents for successful organizational change. Organizational change examines the capabili- 
ties of managers, employees and work environment. It affects employee attitudes and behaviors because of transferring a situation from the known to the Unknown, which can build up uncertainty, strain and anxiety among employees (Shah \& Irani, 2010). There are factors that influenced employee's reaction to organizational change that made employees to support or resist the change initiatives among these perceived organizational support, perceived procedural justice, fear of consequences of a change, self-confidence for learning and development, trust in management and perceived need for change are the factors that influence employee reaction to organizational change.

However, one of the most difficult problems organizations face is dealing with change. In today's rapidly changing, highly competitive environment, the ability to change rapidly, efficiently, and almost continually will distinguish the winners from the losers. Argyris, C. (1999) argue that employees are ultimately responsible for executing change initiatives, and change succeeds or fails depending on employee behavior. Thus, employees' reaction to organizational change is one of the important issues in change management studies.

Today's fast-moving environment requires organizations to undergo changes almost constantly (Jones \& Brazzel, 2006; Kotter, 2010). Working on change organizations relates it to the continual flow of organizational change in order to carry out to do their work more successfully and competently. Change is now becoming the global challenge for every organization because of technology, economic and worldwide modifications that enforce organizations to change. Changes in the organization are necessary with the passage of time through which organizations can gain edge in the market or at least can survive in the rapidly changing market.

The case in our country, Ethiopia, change implementation and management activities was prominent since 1994 when result based performance management system implemented, however; it is strengthened with the implementation of Business Process Reengineering (BPR). Moreover, subsequent change tools were implemented in the public firms afterwards. These include BSC, ISO Standards, and other change management strategies. Although some change management studies exist in our country, they give little concern to employees' reaction towards organizational change rather most of them focus on change management tools.

Accordingly the researcher motivated to investigate this prominent point with preliminary assessment conducted. The researcher came to know that Mekelle revenue and customs authority (MRCA) has implemented change tools after 2009 which may include BPR, BSC, and ISO Standards. As the researcher's observes informally before conducting the study there is a problem in understanding employee's perception before implementing the change initiatives. Therefore, undertaking this topic in MRCA was worth enough to the researcher. Accordingly this study examined employees' reaction to organization change using the following research questions: To what extent perceived organizational sup- 
port affect employee's reaction to change?, To what extent perceived procedural Justice influences employees' response to change, To what extent employees' perceived fears of consequences of a change affect their reaction to change?, To what extent employees' perceived self-confidence for learning and development affect their reaction to change?, To what extent employees' perceived trust in management affect their reaction to change?, to what extent employees' perceived need for change affects their reaction to change?

\section{Literature Summary and Hypothesis Formulations}

The contemporary society marked by confrontation, identification, evaluation, and action process: a process called change (Paton, 2004). In these conditions, the necessity for permanent improvements in performances and continued need for creating new opportunities is likely to cause and/or produce the change. For the organization to survive, it is essential to implement successful change processes (Paton, 2004). Change is a natural and universal process of the world we live in and is never gone. Therefore, the change becomes necessary, inevitable and furthermore is a process of adaptation and evolutionary potential for each person, organization and/or society (Popescu et al., 2012). However, one of the most difficult problems organizations face is dealing with change. In today's rapidly changing, highly competitive environment, the ability to change rapidly, Efficiently, and almost continually will distinguish the winners from the losers. (Argyris, 1999) argues that employees are ultimately responsible for executing change initiatives and change succeeds or fails depending on employee behavior. Change management defined as the introduction and management of initiatives designed at renewing an organization's direction, structure, and capabilities to serve the ever-changing needs of external and internal customers.

Scholars in the field of organizational change generally agree that change initiatives tend to fail more often than they succeed. (Appelbaum et al., 2012) found failure of change initiatives to range from $30 \%$ to $80 \%$, while (Kotter \& Cohen, 2012) estimated that approximately $70 \%$ of all organizational change initiatives fail. Herold and Fedor (2008) estimated that only around $20 \%$ of change initiatives were successful, therefore, failure rate was somewhere between $67 \%-80 \%$. Jones et al. (2008) claim that one of the key reasons for this high failure rate is resistance to change from employees. (Kotter \& Cohen, 2012) also claims that the biggest factor in failed organizational development is the human factor, i.e. attitudes, behaviors and responses by the change recipients. The sixty years quantitative studies reviewed by (Oreg et al., 2011) identifies factors that affect employees' reaction to organizational change which includes that pre change antecedent, change antecedent and change consequence. There are numerous variables within these three factors. Such as change recipient characteristics, internal context, change process perceived benefit/harm is included in these three factors. The variables that examined in this study discussed below. 


\subsection{Perceived Organizational Support}

Perceived organizational support as stated by Eisenberger et al. (1986) is one of the internal contextual variables that can influence the success of a change effort. Previous studies have suggested that perceived organizational support is related to a wide array of work-related attitudes and outcomes (Eisenberger, Fasolo, \& Davis-LaMastro, 1990). Contrarily Organizational members who perceived their work environment as generally unsupportive were more likely to possess cynical reactions, suffer from negative emotions, and ultimately reject the change (Kiefer, 2005; Martin et al., 2005). An employee who sees the employer as supportive is likely to return the gesture. Accordingly, if perceived organization support is correlated with certain decisions of employees, we would then expect that employees are more likely to take into account perceived organizational support when making decisions regarding whether to resist or support organizational change.

In view of the social trade hypothesis (Blau, 1964) and the standard of correspondence (Gouldner, 1960), which have been generally utilized for research on the connection among associations and workers, it very well may be contemplated that representatives' apparent authoritative help influences their sentiment of commitment to their association. In light of the standard of correspondence, representatives will in general react emphatically to great medicines from their manager, or they feel obliged to help the individuals who helped them, inferring a positive standard of correspondence (Gouldner, 1960).

As indicated by Eisenberger et al. (1986), so as to meet socio-enthusiastic requirements and to survey the advantages of expanded work exertion, representatives structure a general observation concerning the degree to which the association esteems their commitments and thinks about their prosperity. Such saw authoritative help will in general be identified with an expansion in Employees' felt commitment to enable the association to arrive at its destinations, their emotional responsibility to the association, and their desire that improved presentation would be remunerated. At the end of the day, saw authoritative help is impacted by different parts of a representative's treatment by the association and, thusly, impacts the worker's understanding of hierarchical thought processes basic that treatment. When perceived organizational support is high, workers are more likely to engage in organizational citizenship behavior (Pernica, 2011).

$\mathrm{H} 1$ : There is a direct relationship between organizational support and employee's reaction to organizational change.

\subsection{Perceived Procedural Justice}

Perceived procedural justice is included in change process factors and it more likely related with employees reaction to change. In particular, several studies linked interactional and procedural justice with reactions to organizational change. As stated in Spreitzer (2002) Procedural justice was asso- 
ciated with higher acceptance, readiness, and commitment to organizational change.

Employees have significant roles in various decision making processes in the organizations. It is sometimes questioned whether the decisions towards employees are fair or not (Colquitt et al., 2001). The behaviors of employees toward justice became an area of study by the increasing importance of concept of justice in the organizations (Greenberg, 1990). It is generally observed that the recent organizational theories focused mostly on the interpersonal interactions and the problems based on these interactions. In this context, it is seen that the concept of social justice is adapted to organizations and accordingly the concept of organizational justice, which refers to the just distribution of organizational outputs depending on organizational relations, has been developed concurrently. Similarly, points out the adaptation of the concept of justice into organizational justice and emerging of it as an important field of study in industrial and organizational psychology (Eberlin \& Tatum, 2008; Bolat, 2010). The fundamental point about the organizational justice is its necessity for the workers personal satisfaction and effective functioning of the organization and to see the absence of organizational justice as a source of problem.

Organizational justice has four types these are distributive, procedural, interpersonal, and informational justice. Distributive justice refers to the distribution of outcomes, i.e. people expect the output to be distributed in accordance with their input. However, this expectation can often not be met when changes are introduced. It is therefore even more important to observe procedural justice in managing organizational changes. Procedural justice is concerned with the way in which results were achieved and the criteria that were applied. Meta-analyses of numerous studies show close connections between procedural justice and job satisfaction, performance, organizational commitment and trust (Colquitt et al. 2001). Accordingly, procedural justice has a major influence on the acceptance or resistance of change processes.

As described in Ince and Gül (2011), recent research data point out that workers react to the decisions that affect them and they are affected by the processes which cause to these decisions. In other words, employees are interested in procedural justice and they try to understand the procedures ending up the decisions made. According to (Folger \& Konovsky 1989) procedural justice is the perception of the processes which are used to determine the decisions. In short, it is about the perceptions of justice related with the decision making processes. Similarly, (Brockner 1996) found that positive individual views of processes and procedural justice were linked to higher levels of trust in the organization and supervisor. Moreover, these authors found that genuinely fair procedures moderated the impact of negative reactions, such as mistrust, that arose from decisions leading to undesirable employee outcomes.

Despite the redundancy of studies in the field of justice in the last twenty years, the valid theoretical data today mostly depends on the Equity Theory of 
Adams in 1965 (Karriker \& Williams, 2009). According to this theory, individuals in the organizations always tend to compare their efforts and gains with the others' efforts and gains (Ince \& Gül, 2011). As described in (Ince \& Gül, 2011) Recent research data point out that workers react to the decisions that affect them and they are affected by the processes which cause to these decisions. The perceptions of justice related with the decision-making processes (Konovsky and Folger, 1991). Similarly, (Brockner 1996) found that positive individual views of processes and procedural justice linked to higher levels of trust in the organization and supervisor. Moreover, these authors found that genuinely fair procedures moderated the impact of negative reactions, such as mistrust, that arose from decisions leading to undesirable employee outcomes.

H2: Having Good procedural justice result a positive affect toward employees reaction to organizational change

\subsection{Fear of Consequences of a Change}

Fear is frequently considered as a factor that triggers workers' protection from change (Agocs, 1997, Kotter \& Cohen, 2012). Be that as it may, for what reason is this so? For the situation before us, where the association is attempting to embrace authoritative change, which is proposed to improve hierarchical execution, dread of known outcomes of a change turns into an obstruction to representatives' acknowledgment of progress, since it applies a pessimistic impact on any individual's normal reasoning. On the off chance that we acknowledge the idea that dread can influence our reasoning and thinking, we may expect that dread can likewise influence our dynamic as a rule and our dynamic concerning a response to change specifically. It isn't difficult to see that researchers have related dread with protection from change. For instance, Dubrin and Ireland (1993) noticed that protection from change is ascribed to workers' dread of helpless results, the obscure, and acknowledgment of traps with the change. In a similar vein, Kotter \& Cohen, 2012 set that dread or frenzy drives self-assurance or immobilization.

Expectation of negative or positive results will lead representatives to fear the change activities. On a few events, researchers considered change beneficiaries' responses to changes that involve negative results, for example, scaling back, a more noteworthy outstanding task at hand, expanded employment multifaceted nature, or loss of occupation control. In these cases, change beneficiaries would in general experience more prominent pressure and mental withdrawal (Ashford, 1988; Axtell et al., 2002), were less open to acknowledge changes (Cunningham et al., 2002), and showed lower levels of employment fulfillment and association (Hall, Goodale, Rabinowitz, \& Morgan, 1978) and lower levels of apparent individual occupation fit (Caldwell et al., 2004), after the change.

There are various clarifications for an issue of why we respond adversely to an 
item or thought while we dread such goal or thought. Initially, dread can smother our discerning reasoning and dynamic, in other words, dread may abbreviate an individual' arrangements of reasoning procedure or span of such procedures since it lessens a lot of data required for settling on a choice and empowers hasty choices. Second, in conditions where dread exists, we may show up at choices that we might not have made in different conditions (Kotter \& Cohen, 2012).

H3: Fear of consequence of change and employees reaction to change has a reciprocal relation

\subsection{Self-Confidence for Learning and Development}

(Vithessonthi \& Schwaninger, 2008) state that employees' self-confidence to learning and development is important factor to support or resist the change in the organization. This means employees who have high level of self-confidence to learning and development may take the change as an opportunity to acquire new skill. On the other hand employees with low level of self-confidence to learning and development may perceive organizational change as a threat.

As cited in Chaiporn \& Vithessonthi (2008) Human resource management research has long included ideas that relate employees' self-confidence in their ability to learning and development on the one hand to work performance on the other. Research into self-confidence for learning and development suggests that humans have different beliefs about the factors responsible for what happens to them. Individuals with an internal locus of control consider what happens to them as determined by factors under their control; on the other hand, individuals with an external locus of control consider what happens to them as determined by factor outside their control.

In the literature, self-confidence is also known as self-efficacy (Maurer, 2001). There has been a growing awareness in the organizational psychology literature that self-efficacy is a key determinant of individuals intention and choice to pursue an activity. Chaiporn \& Vithessonthi (2008) states that employees self-confidence to learning and development is important factor to support or resist the change in the organization which means employees who have high level of self-confidence to learning and development may take the Change as an opportunity to acquire new skill on the other hand employees with low level of self-confidence to learning and development may perceive organizational change as a threat.

H4: self-confidence for learning and development is positively associated to employee's reaction to organizational change

\subsection{Trust in Management}

Trust in the board is a significant variable which remembered for inside setting factors that states by (Oreg et al., 2011). Change beneficiaries who revealed holding elevated levels of trust in the executives, who see the board as steady, 
and who feel regarded, were progressively open to proposed changes and announced a more prominent ability to help out the change (Coyle-Shapiro \& Morrow, 2003; Cunningham et al., 2002; Kiefer, 2005). The significance of trust during authoritative change is broadly revealed in the global writing, predominantly on the grounds that it is considered as a precondition for effective joint effort (for example Huxham \& Vangen, 2003) and showcase direction (Kimura, 2012). It is recognized as a fundamental element of authoritative change and best accomplished through interview, cooperation and strengthening (for example Khan, 1997). As referred to in (Katsaros et al., 2014).

Workers assess the key characteristics of chiefs (for example trustworthiness, fitness, consistency/reasonableness, transparency) or comparative characteristics (for example Mayer, Davis and Schoorman, 1995) agreeing past practices and current circumstances. Further, Costigan, Ilter and Berman (1998) guarantee that representatives trust in the executives depends on the aftereffects of authoritative choices made by the top administration and less on direct understanding of their character, words and activities. In this way, representative trust in the board is deciphered through the association's strategies and practices. Inside this unique situation, different explores show that the presentation of a chief during a change exertion may rely on picking up the trust of their workers (Brockner, Siegel, Daly, Tyler, \& Martin, 1997). Overall; representatives' trust in the executives is a key factor for continuing individual and authoritative viability during hierarchical change.

Earlier examination on authoritative change the board has noticed that when top chiefs endeavor to embrace changes inside their association, they should manufacture trust among their representatives so as to encourage and continue compelling change (Webb, 1996). For sure, top supervisors should construct trust among workers in order to increment hierarchical viability (Argyris, 1962). Furthermore, impression of authenticity of authoritative change can be upgraded by trust in the executives (Rousseau \& Tijoriwala, 1999). A few analysts have noticed that doubt towards those driving changes is one of elements that lead to workers' protection from change. In this way, administrators should pick up their workers trust when they think to start the adjustment in the association.

H5: Trust in management has a direct relation with employee's reaction to organization change.

\subsection{Perceived Need for Change}

For organizational change to emerge there must be some underlying causes or antecedents of a change in an organization. For organizational and/or strategy theorists, a combination of internal and external pressures influences an organization to undertake a certain archetype of organizational changes. For any change to occur, one can expect that most organizations that want to undertake organizational change will communicate their compelling reasons for change to employees at one point in time. Research on organizational change has suggested that a 


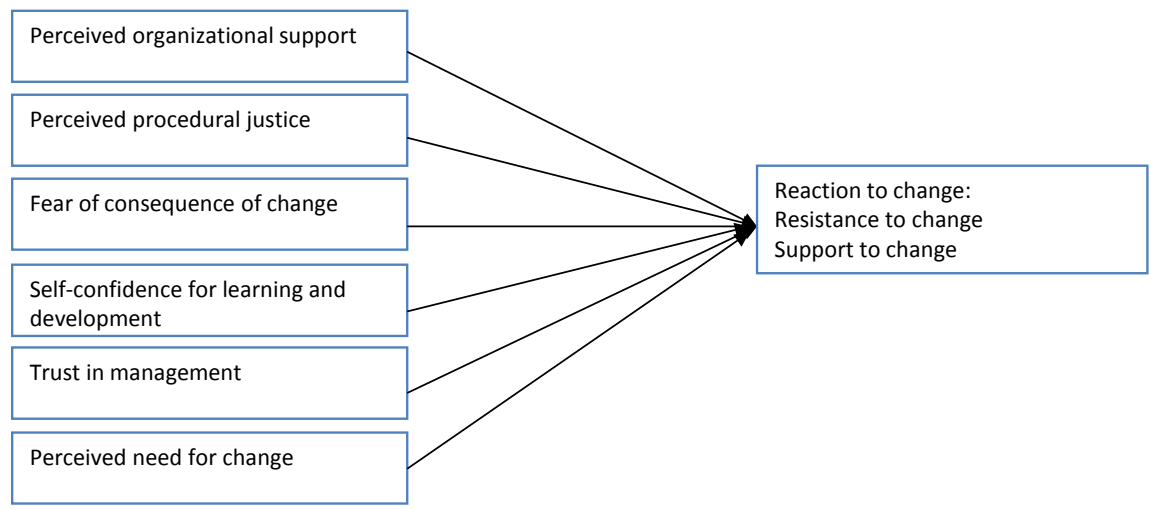

Figure 1. Conceptual framework.

proper communication from management tends to help employees understand a situation and a need for organizational change, thereby facilitating change processes and reducing employees' resistance to change (see, e.g., Kotter 1995; Kotter \& Cohen, 2012).

Research on organizational change has suggested that a proper communication from management tends to help employees understand a situation and a need for organizational change, thereby facilitating change processes and reducing employees' resistance to change (Kotter and Cohen, 2012). It is useful to note that from employee's point of view, the context in which organizational change takes place tends to exert an effect on employees 'perceptions of need for change.

H6: need for change is positively associated with employees reaction to organizational change.

As Figure 1 shows depending on the literature and formulated hypothesis above the study will have the following conceptual frame Work.

\section{Research Methodology}

\subsection{Research Design}

This study uses descriptive research design. This structure is proper to describe realities in accordance with workers discernment towards authoritative change factors utilized in the study. The descriptive method is concerned on describing the existing situation. Close to this illustrative examination configuration utilizing quantitative strategy used to dissect the information gathered from workers. This plan encourages the researcher to clarifying, understanding and anticipating the circumstances and logical results connection between variables.

\subsection{Research Method}

This study utilized quantitative overview technique as a cross sectional investigation in which information was gathered once over the populace utilizing test. As indicated by Creswell (2003) the quantitative overview research configuration is indispensable to make quantifiable causes and influence connection between the factors of the investigation. As referred to in (Bekele et al., 2014). Christen- 
sen (1985) noticed that quantitative overview is the most fitting one to utilize if the motivation behind an examination is to depict the level of relationship which exists between the factors. AS needs be quantitative review strategy utilized in this examination.

\subsection{Participants and Data Collection Procedures}

The data obtained through a self-administrated questionnaire to MRCA employees of seven public intuitions. Questionnaire were distributed to 359 public employees, the researcher utilized example size assurance recipe created at University Park by Jeff Watson, Research Assistant, and Cooperative Extension and Outreach for figuring the example size required.

All questionnaires in this study are measured by using a five-point Likert scale which expressed by strongly disagree (1), disagree (2), neutral (3), agree (4) and strongly agree (5). Statistical Package for Social Science (SPSS) software employed to analyze and present the data by using different statistical tools.

Cronbach's alpha is a coefficient of unwavering quality. It is normally utilized as a proportion of the inward consistency or unwavering quality of a psychometric grade for an example of examinees. A few creators, for example, Alwadaei (2010), express that an instrument that gives an unwavering quality coefficient of .70 is typically considered as a dependable instrument. Subsequently, in this investigation the inward consistency for all things of the instrument was tried utilizing Cronbach's alpha strategy. In this manner the researcher utilized the previously mentioned writing into thought and tried the unwavering quality of the things which were created for respondents.

As indicated in Table 1, five things were utilized to estimated protection from change. Respondents were approached to report how much they concur with

Table 1. Reliability test.

\begin{tabular}{ccc}
\hline Variables & Number of items & Cronbach's alpha \\
\hline RC & 5 & .870 \\
SC & 5 & .908 \\
POS & 6 & .901 \\
PPJ & 8 & .894 \\
FCC & 3 & .858 \\
SCLD & 3 & .879 \\
TM & 6 & .913 \\
PNC & 2 & .874
\end{tabular}

Source: Own source 2020. Where: $\mathrm{RC}=$ resistance to change; $\mathrm{SC}=$ Support to change; POS = Perceived organizational support; PPJ = Perceived Procedural justice; FCC = Fear of consequence of change; SCLD = Self Confidence for learning and development; $\mathrm{TM}=$ Trust in management; $\mathrm{PNC}=$ Perceived need for change. 
every one of things utilizing a five-point scale going from 1 (emphatically deviate) to 5 (firmly concur). The Cronbach's alpha for this variable was (.870).

Support for change a total of five items were designed to measure the level of employees support to the change using a five point Likert-type scale. The coefficient of reliability for this scale is (.908).

Perceived organizational support was measured using a six -item measure reflecting perceived organizational support. Respondents were asked to indicate the degree to which they agreed with these items. The Cronbach's alpha is (.901)

Perceptions of procedural justice were measured with eight-item Employees responded to each item about their perception of justice and Cronbach's alpha for procedural justice in this study is (.894).

Fear of consequence of change was measured using four items. Respondents were asked to report the degree to which they agreed with these items the cronbach's alpha for this variable is (.858).

Fearlessness for learning and improvement was estimated utilizing a three-thing measure. Respondents demonstrated how much they concurred with these things following the strategy, the proportion of fearlessness for learning and improvement incorporated each of the three things Cronbach's alpha is (.879).

Trust in the board estimated utilizing a six things measure Respondents were approached to demonstrate how much they concurred with these things utilizing a five-point scale each of the six things were created to quantify trust in the executives. Subsequently, Cronbach's alpha is (.913).

Perceived need for change was measured using a two items which reflecting employee's perception of need for a change in the organization. Respondents were asked to indicate the degree to which they agreed with the items. The Cronbach's alpha is (.874).

\subsection{Data Processing and Analyzing}

Descriptive analysis, correlation analysis and multiple regression analysis statistical tools employed to analyze the data. According to (Abebe, 2016) as cited in (Bekele et al., 2014) the mean score below 3.39 was considered as low, the mean score from 3.40 up to 3.79 was considered as moderate and mean score above 3.8 was considers as high correlation coefficient can range from -1.00 to +1.00 . The value of -1.00 represents a perfect negative correlation. While a value of +1.00 represents a perfect positive correlation. A value of .00 correlations represents no relationship as stated in (Cohen et al., 2002). Multiple regression analysis takes into account the inter-correlations among all variables involved. This method also takes into account the correlations among the predictor scores. Multiple regression analysis more than one predictor is jointly regressed against the criterion variable.

$$
\begin{aligned}
& R C=\beta 0+\beta 1 P O S+\beta 2 P P J+\beta 3 T M+\beta 4 F C C+\beta 5 S C L D+\beta 6 P N C+e \\
& S C=\beta 0+\beta 1 P O S+\beta 2 P P J+\beta 3 T M+\beta 4 F C C+\beta 5 S C L D+\beta 6 P N C+e
\end{aligned}
$$


Mathematically,

$$
Y i=\beta 1+\beta 2 X 2+\beta 3 X 3+\beta 4 X 4+\beta 5 X 5+\beta 6 X 6+\beta 7 X
$$

where $Y$ is the dependent variable-reaction to change $X 2, X 3, X 4, X 5, X 6$ and $X 7$ are the explanatory variables (or the regressors) $\beta 1$ is the intercept term, it gives the mean or average effect on $Y$ of all the variables excluded from the equation, although its mechanical interpretation is the average value of $Y$ when the stated independent variables are set equal to zero.

$\beta 2, \beta 3, \beta 4, \beta 5, \beta 6, \beta 7$ refer the coefficient of their respective independent variable which measures the change in the mean value of $Y$, per unit change in their respective independent variables.

\section{Data Analysis Results and Discussions}

Table 2: indicates employee's perception towards the change, mean score of perceived organizational support, perceived procedural justice, perceived need for change have moderate mean $(3.78,3.52,3.68)$ respectively. which indicates that employees of MRCA believes that they get moderate level of support from their organization they also think there is moderate level of procedural justice as well as their need for undertaking the change is moderate. Self-confidence for learning and development and trust management has largest mean, which is $(3.88,3.89)$. It indicates that, employees of MRCA have high self-confidence for learning and development, they trusted their manager highly, and their standard deviation show slightly different, which was perceived need for change (1.055), and perceived procedural justice (1.022) and perceived organization support (1.102) and trust in management (1.175) unlike these variables, self-confidence for learning and development has low standard deviation which is (.990), fear of consequence of change has low mean score (2.49) with standard deviation (.992) While the dependent variable reaction to change which expressed by employee's resistance to change and support to change mean assessment show

Table 2. Results of Descriptive analysis.

\begin{tabular}{cccccc}
\hline \multicolumn{5}{c}{ Descriptive Statistics } \\
\hline RC & N & Minimum & Maximum & Mean & Std. Deviation \\
\hline SC & 359 & 1 & 5 & 2.18 & .917 \\
POS & 359 & 1 & 5 & 3.80 & .895 \\
PPJ & 359 & 1 & 5 & 3.78 & 1.102 \\
FCC & 359 & 1 & 5 & 3.52 & 1.022 \\
SCLD & 359 & 1 & 5 & 2.49 & .992 \\
TM & 359 & 1 & 5 & 3.88 & .990 \\
PNC & 359 & 1 & 5 & 3.89 & 1.175 \\
\hline
\end{tabular}


2.18 and 3.80 respectively. As cited in (Abebe, 2016) the mean score below 3.39 was considered as low, the mean score from 3.40 up to 3.79 was considered as moderate and mean score above 3.8 was considers as high. according to this information resistance to change scores low mean and support to change was lied on high mean which means the employees in MRCA have low resistance to change rather they support the change.

As Table 3 indicates there is negative, significant and substantial correlation between perceived organizational support and resistance to change $(\mathrm{r}=-.624, p$ $<.01$ ), and there is positive, significant and substantial correlation between perceived organizational support and support of change $(r=.574, p<.01)$. The other correlation result showed that perceived procedural justice and resistanceto change has negative, significant and substantial correlation $(\mathrm{r}=-.592, p<.01)$, and perceived procedural justice and support of change are in a substantial way

Table 3. Results of inferential statistics.

\begin{tabular}{|c|c|c|c|c|c|c|c|c|c|}
\hline \multicolumn{10}{|c|}{ Correlations } \\
\hline & & $\mathrm{RC}$ & SC & POC & PPJ & FCC & SCLD & TM & PNC \\
\hline \multirow{3}{*}{$\mathrm{RC}$} & Correlation & 1 & & & & & & & \\
\hline & Sig. (2-tailed) & & & & & & & & \\
\hline & $\mathrm{N}$ & 359 & & & & & & & \\
\hline \multirow{3}{*}{ SC } & Correlation & $-.824^{* *}$ & 1 & & & & & & \\
\hline & Sig. (2-tailed) & .000 & & & & & & & \\
\hline & $\mathrm{N}$ & 359 & 359 & & & & & & \\
\hline \multirow{3}{*}{ POS } & Correlation & $-.624^{* *}$ & $.574^{\star *}$ & 1 & & & & & \\
\hline & Sig. (2-tailed) & .000 & .000 & & & & & & \\
\hline & $\mathrm{N}$ & 359 & 359 & 359 & & & & & \\
\hline \multirow{3}{*}{ PPJ } & Correlation & $-.592^{\star *}$ & $.538^{* *}$ & $.356^{* *}$ & 1 & & & & \\
\hline & Sig. (2-tailed) & .000 & .000 & .000 & & & & & \\
\hline & $\mathrm{N}$ & 359 & 359 & 359 & 359 & & & & \\
\hline \multirow{3}{*}{ FFC } & Correlation & $.591^{\star \star}$ & $-.511^{\star \star}$ & $-.447^{\star *}$ & $-.325^{\star \star}$ & 1 & & & \\
\hline & Sig. (2-tailed) & .000 & .000 & .000 & .000 & & & & \\
\hline & $\mathrm{N}$ & 359 & 359 & 359 & 359 & 359 & & & \\
\hline \multirow{3}{*}{ SCLD } & Correlation & $-.430^{* *}$ & $.381^{* *}$ & $.271^{\star *}$ & $.250^{* *}$ & $-.192^{\star \star}$ & 1 & & \\
\hline & Sig. (2-tailed) & .000 & .000 & .000 & .000 & .000 & & & \\
\hline & $\mathrm{N}$ & 359 & 359 & 359 & 359 & 359 & 359 & & \\
\hline \multirow{3}{*}{$\mathrm{TM}$} & Correlation & $-.837^{* *}$ & $.707^{* *}$ & $.562^{\star *}$ & $.521^{\star *}$ & $-.490^{* *}$ & $.298^{* *}$ & 1 & \\
\hline & Sig. (2-tailed) & .000 & .000 & .000 & .000 & .000 & .000 & & \\
\hline & $\mathrm{N}$ & 359 & 359 & 359 & 359 & 359 & 359 & 359 & \\
\hline \multirow{3}{*}{ PNC } & Correlation & $.371^{* *}$ & $.402^{* *}$ & $.204^{* *}$ & $.317^{\star *}$ & $-.250^{* *}$ & $.301^{* *}$ & $289^{* *}$ & 1 \\
\hline & Sig. (2-tailed) & .000 & .000 & .000 & .000 & .000 & .000 & .000 & \\
\hline & $\mathrm{N}$ & 359 & 359 & 359 & 359 & 359 & 359 & 359 & 359 \\
\hline
\end{tabular}

**. Correlation is significant at the .01 level (2-tailed). 
correlated positively and significantly $(r=.538, p<.01)$, Fear of consequence of change was the other variable in the study the result of correlation for this variable indicated that Fear of consequence of change positively, significantly and in a substantial way correlated with resistance to change $(r=.524, p<.01)$ and negatively, significantly and in a medium way correlated with support for change $(\mathrm{r}=$ -.477, $p<.01$ ), Self-confidence for learning and development also negatively, significantly and in a medium way correlated with resistance to change $(\mathrm{r}=$ $-.430, p<.01)$ and has positive, significant and medium correlation with support of change( $\mathrm{r}=.381, p<.01)$, employees will support if they have self-confidence for learning and development otherwise they will oppose the change. Trust in management negatively, significantly and in a very strong association correlated with resistance to change $(\mathrm{r}=-.837, p<.01)$ and very strong association, negative and significant correlation with support of change $(.707, p$ $<.01)$, The other finding of the study shows that Perceived need for change negatively and significantly correlated in medium range with resistance to change $(\mathrm{r}=-.371, p<.01)$ and correlated positively, significantly and in a medium way with support of change $(\mathrm{r}=.402, p<.01)$.

As of Table 4 Standing from the result of the above, multiple regression analysis the value of F statics 231.700 at 6 and 352 degree of freedom is statically significant at $95 \%$ confidence. Which means that model is statically significant. Additionally; $\mathrm{R}^{2}$ of the model is .798 , which shows that approximately 79.8 of variance in independent (resistance to change) can be explained by the linear combination of the independent variables.

As we can understand from Table 5 the result of multiple regressions analysis shows the value of F statics 94.538 at 6 and 352 degree of freedom is statically significant. Furthermore, the $\mathrm{R}^{2}$ of the model is 617 , which shows that approximately $61.7 \%$ of the variance in dependent variable (support to change) explained by the linear combination of the independent variable.

Table 4. Regression results for Resistance to change.

\begin{tabular}{cccccc}
\hline \multicolumn{5}{c}{ 1) Model summary } \\
\hline Model & $\mathrm{R}$ & $\mathrm{R}^{2}$ & Adjusted $\mathrm{R}^{2}$ & $\mathrm{~F}$ & Sig \\
& $.893 \mathrm{a}$ & .798 & .795 & 231.700 & $.000 \mathrm{~b}$ \\
\hline \multicolumn{7}{c}{ 2) Beta coefficients } \\
\hline Model & Un-standardized B & Std. Err. & Standardized & $\mathrm{T}$ & Sig \\
(Constant) & 5.419 & .151 & & 35.879 & .000 \\
POS & -.147 & .024 & -.177 & -6.025 & .000 \\
PPJ & -.135 & .026 & -.150 & -5.172 & .000 \\
FCC & .091 & .023 & .099 & 3.948 & .000 \\
SCLD & -.138 & .024 & -.149 & -5.724 & .000 \\
TM & -.449 & .025 & -.574 & -17.754 & .000 \\
PNC & -.049 & .023 & -.056 & -2.134 & .034 \\
\hline
\end{tabular}


Table 5. Regression results for Support to change.

\begin{tabular}{cccccc}
\hline \multicolumn{5}{c}{ 1) Model Summary } \\
\hline model & $\mathrm{R}$ & $\mathrm{R}^{2}$ & Adjusted $\mathrm{R}^{2}$ & $\mathrm{~F}$ & Sig \\
& $.786 \mathrm{a}$ & .617 & .611 & 94.538 & $.000 \mathrm{~b}$ \\
\hline Model & Un-standardized B & Std.Err. & Standardized & $\mathrm{T}$ & Sig \\
(constant $)$ & .714 & .203 & & 3.518 & .000 \\
POC & .174 & .033 & .214 & 5.310 & .000 \\
PPJ & .138 & .035 & .158 & 3.956 & .000 \\
FCC & -.048 & .031 & -.053 & -1.532 & .126 \\
SCLD & .102 & .032 & .112 & 3.131 & .002 \\
TM & .317 & .034 & .416 & 9.348 & .000 \\
PNC & .121 & .031 & .143 & 3.933 & .000 \\
\hline
\end{tabular}

Table 6. Summary results of Hypothesis.

\begin{tabular}{|c|c|c|c|c|c|c|c|}
\hline \multirow{2}{*}{ Hypothesis } & \multirow{2}{*}{$\begin{array}{l}\text { Mean } \\
\text { score }\end{array}$} & \multicolumn{2}{|c|}{ Descriptive results } & \multirow{2}{*}{$\begin{array}{l}\text { Correlation } \\
\text { result for } \\
\text { resistance to } \\
\text { change }\end{array}$} & \multirow{2}{*}{$\begin{array}{l}\text { Correlation } \\
\text { result for } \\
\text { support to } \\
\text { change }\end{array}$} & \multirow{2}{*}{$\begin{array}{l}\text { Regression } \\
\text { result for } \\
\text { resistance } \\
\text { to change }\end{array}$} & \multirow{2}{*}{$\begin{array}{c}\text { Regression } \\
\text { result for } \\
\text { support to } \\
\text { change }\end{array}$} \\
\hline & & $\begin{array}{c}\text { Std. } \\
\text { Deviation }\end{array}$ & $\begin{array}{l}\text { Level of } \\
\text { relation }\end{array}$ & & & & \\
\hline $\mathrm{H} 1$ & 3.78 & 1.102 & Moderate & -ve & $+\mathrm{ve}$ & $\begin{array}{c}\text { Statically } \\
\text { significant }\end{array}$ & $\begin{array}{c}\text { Statically } \\
\text { significant }\end{array}$ \\
\hline $\mathrm{H} 2$ & 3.52 & 1.022 & Moderate & -ve & $+\mathrm{ve}$ & “ & “ \\
\hline $\mathrm{H} 3$ & 3.68 & 1.055 & Moderate & +ve & $-\mathrm{ve}$ & “ & “ \\
\hline $\mathrm{H} 4$ & 3.88 & .99 & High & $-\mathrm{ve}$ & $+\mathrm{ve}$ & “ & “ \\
\hline $\mathrm{H} 5$ & 3.89 & 1.175 & High & $-\mathrm{ve}$ & $-\mathrm{ve}$ & “ & “ \\
\hline H6 & 3.87 & 1.164 & high & - ve & +ve & “ & “ \\
\hline
\end{tabular}

The correspondence analysis in Table 6 shows Managing Organizational change is difficult task, because it can create a kind of comprehensive negative emotion usually contains stress, depression, anxiety and other negative emotions. MRCA can perform effective organizational change by conducting the following activates:

1) Fear of progress fundamentally ascends through misconception about the change. So as to stay away from such issue MRCA ought to acknowledge about the change essential from workers and after that the top administrator of the organization can choose about the progressions that the organization merits.

2) Teaching, offering preparing to representatives about the progressions that the organization may confront/merit later on time is essential to know workers about the change and to make a functioning and successful interest during the hour of progress. 
3) Sharing great experience of viable association change made by other association is significant and afterward relating that involvement in culture and nature of the association is vital.

\section{Conclusion and Future Directions}

Workers of MRCA accept that they get moderate degree of help from their organization. They additionally think there is moderate degree of procedural equity just as their requirement for undertaking the change is moderate. Self-assurance for learning and improvement and trust of the board has the biggest mean which shows that, workers of MRCA have high self-assurance for learning and advancement and they have confided in their administrator profoundly. Their standard deviation shows marginally unique which was seen requirement for change, saw procedural equity, saw hierarchical help and trust in the executives. In contrast to these factors, self-assurance for learning and advancement has low standard deviation which is fear of change, and has low mean score with standard deviation. The needy variable response to change which communicated by worker's protection from change and backing to change mean appraisal showed fear of change scores low mean and backing to change was lied on high mean which implies the representatives in MRCA have low protection from change rather they bolster the change. On the other hand, fear of unknown consequences of change positively and significantly correlated with resistance to change and negatively and significantly correlated with support to change.

Fear of change was the other variable in the investigation of the aftereffect of relationship for this variable which demonstrated that fear of result of progress decidedly, altogether and in a generous path corresponded with protection from change and adversely, essentially and in a medium route connected with help for change. Self-assurance for learning and improvement likewise contrarily, essentially and in a medium route corresponded with protection from change and had a positive, huge and medium relationship with help of progress. Representatives will bolster on the off chance that they have fearlessness for learning and improvement else they will contradict the change. Trust in the executives contrarily, essentially and in an extremely solid affiliation corresponded with protection from change and solid affiliation, negative and noteworthy relationship with help of progress. The other finding of the investigation shows that perceived requirement for change adversely and altogether associated in medium range with protection from change and connected decidedly, fundamentally and in a medium path with help of progress.

Likewise, as showed in multiple regression analysis measurements of saw representatives conduct towards hierarchical change which are seen authoritative help, saw procedural equity, fearlessness to learning and improvement, trust in the executives and saw requirement for change have negative and critical impact on protection from change while it is certain and noteworthy impact on help to 
change. In contrast to this dread of result of progress is sure and huge impact on protection from change while it is irrelevant to help to change. Finally, the overall finding in this study supports the notion that how Employees perceive or feel during organizational change has significant implications for their decisions to take reaction to change by support or resist the change.

This study is undertaken by considering the direct effect between perceived employees' behavior and their reaction towards organizational change. However, there will be variables that have a mediating role such as communication psychological contract etc. therefore; future researchers should consider these mediating variables. Furthermore, this study was limited to MRCA Tigrai region. Hence, it will be good for future researchers to focus on industry wise and other Regions in Ethiopia.

\section{Conflicts of Interest}

The authors declare no conflicts of interest regarding the publication of this paper.

\section{References}

Abebe, M. (2016). Assessment on Employees' Attitude towards the Implementation of Private Pension Scheme: The Case of Save the Children International. Addis Ababa: Addis Ababa University.

Agocs, C. (1997). Institutionalized Resistance to Organizational Change: Denial, Inaction and Repression. Journal of Business Ethics, 16, 917-931. https://doi.org/10.1023/A:1017939404578

Agocs, C. (1997). Institutionalized Resistance to Organizational Change: Denial, Inaction and Repression. Journal of Business Ethics, 16, 917-931. https://doi.org/10.1023/A:1017939404578

Alwadaei, S. (2010). Employee's Perception of, and Satisfaction with, Performance Appraisal.

Appelbaum, S. H., Habashy, S., Malo, J. L., \& Shafiq, H. (2012). Back to the Future: Revisiting Kotter's 1996 Change Model. Journal of Management Development, 31, 764-782. https://doi.org/10.1108/02621711211253231

Argyris, C. (1962). Interpersonal Competence and Organizational Effectiveness. Homewood, IL: Dorsey Press.

Argyris, C. (1999). On Organizational Learning (2nd ed.). Oxford: Blackwell.

Ashford, S. J. (1988). Individual Strategies for Coping with Stress during Organizational Transitions. Journal of Applied Behavioral Science, 24, 19-36. https://doi.org/10.1177/0021886388241005

Axtell, C., Wall, T., Stride, C., Pepper, K., Clegg, C., Gardner, P., \& Bolden, R. (2002). Familiarity Breeds Content: The Impact of Exposure to Change on Employee Openness and Well-Being. Journal of Occupational and Organizational Psychology, 75, 217-231. https://doi.org/10.1348/09631790260098596

Bekele, Z., Shigutu, A. D., \& Tensay, A. T. (2014). The Effect of Employees' Perception of Performance Appraisal on Their Work Outcomes. International Journal of Management and Commerce Innovations, 2, 136-173.

Blau, P. (1964). Exchange and Power in Social Life. New York, NY: Wiley. 
Bolat, O. (2010). The Relationships between Leader-Member Exchange and Organizational Justice in Hotels. European Journal of Economics, Finance and Administrative Sciences, 26, 115-125.

Bridges, W. (1980). Transitions: Making Sense of Life's Changes. Reading, MA: Addison-Wesley.

Brockner, J. (1996). Understanding the Interaction between Procedural and Distributive Justice: The Role of Trust. In R. M. Kramer \& T. T. Tyler (Eds.), Trust in Organizations: Frontiers of Theory and Research (pp.390-413). https://doi.org/10.4135/9781452243610.n18

Brockner, J., Siegel, P., Daly, J., Tyler, T., \& Martin, C. (1997). When Trust Matters: The Moderating Effect of Outcome Favorability. Administrative Science Quarterly, 42, 558-583. https://doi.org/10.2307/2393738

Caldwell, S. D., Herold, D. M., \& Fedor, D. B. (2004). Toward an Understanding of the Relationships among Organizational Change, Individual Differences, and Changes in Person-Environment Fit: A Cross-Level Study. Journal of Applied Psychology, 89, 868-882. https://doi.org/10.1037/0021-9010.89.5.868

Cohen, J. R., Swerdlik, M. E., \& Philips, S. M. (2002). Validity. In R. J. Cohen, \& M. E. Swerdlik's (Eds.), Psychological Testing and Assessment: An Introduction to Test and Measurement (pp. 154-187). Columbus, OH: McGraw-Hill.

Cohn, R. J., \& Swerdlink, M. E. (2002). Psychological Testing and Assessment: An Introduction to Tests and Measurements (5th ed)., New York: McGraw-Hill.

Colquitt, J., Conlon, D., Wesson, M., \& Porter, C. (2001). Justice at the Millennium: A Meta-Analytic Review of 25 Years of Organizational Justice Research. Journal of Applied Psychology, 86, 425-445. https://doi.org/10.1037/0021-9010.86.3.425

Costigan, R., Ilter, S., \& Berman, J. (1998). A Multi-Dimensional Study of Trust in Organizations. Journal of Management Issues, 10, 303-317.

Coyle-Shapiro, J. A., \& Morrow, P. C. (2003). The Role of Individual Differences in Employee Adoption of TQM Orientation. Journal of Vocational Behavior, 62, 320-340. https://doi.org/10.1016/S0001-8791(02)00041-6

Creswell, J. (2003). Research Design: Qualitative, Quantitative and Mixed Method Approach (2nd ed.) Thousand Oaks, C A: Sage Publications.

Cunningham, C. E., Woodward, C. A., Shannon, H. S., MacIntosh, J., Lendrum, B., Rosenbloom, D., \& Brown, J. (2002). Readiness for Organizational Change: A Longitudinal Study of Workplace, Psychological and Behavioural Correlates. Journal of Occupational and Organizational Psychology, 75, 377-392. https://doi.org/10.1348/096317902321119637

Dubrin, A., \& Ireland, R. (1993). Management \& Organization (2nd ed.). Cincinnati, OH: Southwestern College Publishing Company.

Eberlin, R., \& Tatum, B. (2008). Making Just Decisions: Organizational Justice, Decision Making, and Leadership. Management Decision, 46, 310-329. https://doi.org/10.1108/00251740810854177

Eisenberger, R., Fasolo, P., \& Davis, V. (1990). Perceived Organizational Support and Employee Diligence, Commitment, and Innovation. Journal of Applied Psychology, 75, 51-59. https://doi.org/10.1037/0021-9010.75.1.51

Eisenberger, R., Huntington, R., Hutchison, S., \& Sowa, D. (1986). Perceived Organizational Support. Journal of Applied Psychology, 71, 500-507. https://doi.org/10.1037/0021-9010.71.3.500

Folger, R., \& Konovsky, M. (1989). Effects of Procedural and Distributive Justice on 
Reactions to Pay Raise Decisions. Academy of Management Journal, 32, 115-130. https://doi.org/10.2307/256422

Gouldner, A. (1960). The Norm of Reciprocity: A Preliminary Statement. American Sociological Review, 25, 161-178. https://doi.org/10.2307/2092623

Greenberg, J. (1990). Employee Theft as a Reaction to Underpayment in Equity: The Hidden Cost of Pay Cuts. Journal of Applied Psychology, 75, 561-568. https://doi.org/10.1037/0021-9010.75.5.561

Hall, D. T., Goodale, J. G., Rabinowitz, S., \& Morgan, M. A. (1978). Effects of Top-Down Departmental and Job Change upon Perceived Employee Behavior and Attitudes: A Natural Field Experiment. Journal of Applied Psychology, 63, 62-72.

https://doi.org/10.1037/0021-9010.63.1.62

Herold, D., \& Fedor, D. (2008). The Effects of Transformational and Change Leadership on Employees' Commitment to a Change: A Multilevel Study. Journal of Applied Psychology, 93, 346-357. https://doi.org/10.1037/0021-9010.93.2.346

Huxham, C., \& Vangen, S. (2003). Researching Organizational Practice through Action Research: Case Studies and Design Choices. Organizational Research Methods, 6, 383-403. https://doi.org/10.1177/1094428103254454

Ince, M., \& Gül, H. (2011). The Effect of Employees' Perceptions of Organizational Justice on Organizational Citizenship Behavior: An Application in Turkish Public Institutions. International Journal of Business and Management, 6, 134-149. https://doi.org/10.5539/ijbm.v6n6p134

Jones, B., Brazzel, M., \& NTL Institute for Applied Behavioral Science (2006). The NTL Handbook of Organization Development and Change: Principles, Practices, and Perspectives. San Francisco, CA: Pfeiffer.

Karriker, J. H., \& Williams, M. L. (2009). Organizational Justice and Organizational Citizenship Behavior: A Mediated Multifoci Model. Journal of Management, 35, 112-135. https://doi.org/10.1177/0149206307309265

Katsaros, K. K., Tsirikas, A. N., \& Bani, S.-M. (2014). Exploring Employees' Perceptions, Job-Related Attitudes and Characteristics during a Planned Organizational Change. International Journal of Business Science and Applied Management, 9, 36-50.

Khan, S. (1997). The Key to Be a Leader Company: Empowerment. Journal of Quality and Participation, 20, 44-50.

Kiefer, T. (2005). Feeling Bad: Antecedents and Consequences of Negative Emotions in Ongoing Change. Journal of Organizational Behavior, 26, 875-897. https://doi.org/10.1002/job.339

Kimura, T. (2012). Transformational Leadership and Job Satisfaction: The Mediating Effects of Perceptions of Politics and Market Orientation in the Japanese Context. International Journal of Business Science and Applied Management, 7, 29-42.

Konovsky, M. A., \& Folger, R. (1991). The Effects of Procedures, Social Accounts, and Benefits Level on Victims' Layoff Reactions. Journal of Applied Social Psychology, 21, 630-650. https://doi.org/10.1111/j.1559-1816.1991.tb00540.x

Kotter, J. (1995). Leading Change: Why Transformation Efforts Fail. Harvard Business Review, 73, 59-67.

Kotter, J. P. (2010). Power and Influence. Simon and Schuster. New York: Free Press.

Kotter, J. P., \& Cohen, D. S. (2012). The Heart of Change: Real-Life Stories of How People Change Their Organizations. Cambridge, MA: Harvard Business Press.

Martin, A. J., Jones, E. S., \& Callan, V. J. (2005). The Role of Psychological Climate in a Facilitating Employee Adjustment during Organizational Change. European Journal of 
Work and Organizational Psychology, 14, 263-283.

https://doi.org/10.1080/13594320500141228

Maurer, T. (2001). Career-Relevant Learning and Development, Worker Age, and Beliefs about Self-Efficacy for Development. Journal of Management, 27, 123-140. https://doi.org/10.1177/014920630102700201

Oreg, S., Vakola, M., \& Armenakis, A. (2011). Change Recipients' Reactions to Organizational Change: A 60-Year Review of Quantitative Studies. The Journal of Applied Behavioral Science, 47, 461-524. https://doi.org/10.1177/0021886310396550

Paton, A. (2004). Save the Beloved Country (3rd American ed.). New York: Pocket Books.

Pernica, M. K. (2011). Organizational Change and Employee Trust: The Mediating Roles of Perceived Organizational Support and Organizational Justice. Ottawa: Carleton University.

Pernica, M. K. (2011). Organizational Change and Employee Trust: The Mediating Roles of Perceived Organizational Support and Organizational Justice. Carleton: Carleton University.

Popescu, D., Ciocârlan-Chitucea, A., Steriu, A., \& State, C. (2012). Change Management Condition of Organizational Sustainability in IT \& C Small and Medium-Sized Enterprises. Sustainability and Organizational Change, 14, 333-348.

Rousseau, D., \& Tijorilawa, S. (1999). What's a Good Reason to Change? Motivated Reasoning and Social Accounts in Promoting Organizational Change. Journal of Applied Psychology, 84, 514-528. https://doi.org/10.1037/0021-9010.84.4.514

Shah, N., \& Irani, Z. (2010). Examining Employee Attitudes and Behaviours towards Organizational Change Using Supervisor and Peer Relations. European, Mediterranean and Middle Eastern Conference on Information Systems, Abu Dhabi, UAE, 12-13 April 2010, 1-15.

Spreitzer, G., \& Mishra, A. (2002). To Stay or to Go: Voluntary Survivor Turnover Following an Organizational Downsizing. Journal of organizational Behavior, 23, 707-729. https://doi.org/10.1002/job.166

Vithessonthi, C., \& Schwaninger, M. (2008). Job Motivation and Self-Confidence for Learning and Development as Predictors of Support for Change. Journal of Organisational Transformation \& Social Change, 5, 141-157. https://doi.org/10.1386/jots.5.2.141_1

Vithessonthi, S., Chaiporn, V., \& Markus, S. (2008). Job Motivation and Self-Confidence for Learning and Development as Predictors of Support for Change. Journal of organizational Transformation and Social Change, 5, 141-157.

https://doi.org/10.1386/jots.5.2.141_1

Webb, E. (1996). Trust and Crisis. In R. Kramer and T. Tyler (Eds.), Trust in Organizations: Frontiers of Theory and Research (pp. 288-302). Thousand Oaks, CA: Sage. https://doi.org/10.4135/9781452243610.n14 